\title{
Os processos de formação na Política Nacional de Humanização: a experiência de um curso para gestores e trabalhadores da atenção básica em saúde
}

\author{
| ${ }^{1}$ Carla Ribeiro Guedes, ${ }^{2}$ Luciana Bettini Pitombo, \\ ${ }^{3}$ Maria Elizabeth Barros de Barros |
}

Resumo: Este artigo tem como objetivo relatar a experiência de um curso de formação da Política Nacional de Humanização voltado para gestores e trabalhadores da atenção básica de um município no estado do Rio de Janeiro. O curso visou a formação de apoiadores institucionais capazes de fomentar rede no Sistema Único de Saúde (SUS), promover mudanças e consolidação nos modos de atenção e de gestão dos serviços. Como referencial metodológico, buscou-se um modo de "formação-intervenção" que fosse baseado em práticas concretas de intervenção dos trabalhadores nos processos de trabalho em saúde. O curso envolveu quarenta participantes, gestores e trabalhadores de nível médio e superior, ligados à atenção básica, oriundos da Estratégia de Saúde da Família e de Unidades de Saúde. Como resultados destacam-se ações de co-gestão no formato de reuniôes com os usuários para o compartilhamento de decisōes relativas ao serviço; implementação de acolhimento, com intervenções que garantam o acesso do usuário ao serviço; e de clínica ampliada, com discussões em equipe dos casos clínicos; e açōes no campo da saúde do trabalhador, como efeito das discussōes dos processos de trabalho nas equipes multiprofissionais.

> Palavras-chave: Política Nacional de Humanização; processo de formação, curso, atenção básica.

\author{
1 Psicóloga, doutora em Saúde \\ Coletiva pelo IMS-UERJ \\ consultora da Política Nacional \\ de Humanização do Ministério \\ da Saúde. Endereço eletrônico: \\ carla.rguedes@gmail.com \\ 2 Psicóloga, mestre em \\ Psicologia pela Universidade \\ Federal Fluminense, consultora \\ da Política Nacional de \\ Humanização do Ministério da \\ Saúde. Endereço eletrônico: \\ lupitombo@yahoo.com.br \\ ${ }^{3}$ Psicóloga, professora adjunta \\ na Universidade Federal do \\ Espírito Santo, consultora \\ da Política Nacional de \\ Humanização do Ministério da \\ Saúde. Endereço eletrônico: \\ barros.bete@gmail.com
}


Este artigo tem como objetivo apresentar a experiência de um curso de formação voltado para gestores e trabalhadores do sistema de saúde de um município $^{1}$ no Estado do Rio de Janeiro. Formulado a partir de uma parceria entre o Ministério da Saúde/Secretaria de Atenção à Saúde/Política Nacional de Humanização e a Secretaria Municipal de Saúde do município em questão, no ano de 2008, o curso visou à formação de multiplicadores da PNH no âmbito da atenção básica de saúde.

A Política Nacional de Humanização (PNH), conforme documentos e artigos produzidos nos últimos cinco anos (BRASIL, 2008; BARROS, 2005; BARROS; BENEVIDES, 2007; BENEVIDES; PASSOS, 2005 a, 2005 b; HECKERT; NEVES, 2007; SANTOS FILHO, 2009), vem afirmando uma política pública de saúde que não se reduz ao seu caráter governamental. Como política pública, portanto processual, se constrói a partir das experiências do SUS, dos processos de trabalho em curso nos serviços de saúde, afirmando-se nas práticas concretas dos trabalhadores, usuários e gestores que compõem o Sistema Único de Saúde (SUS) no nosso país.

A experiência vivida no curso de formação realizado no referido município, ao seguir os princípios da $\mathrm{PNH}$, se estabeleceu como mais uma aposta num modo de trabalhar em saúde, um modo de existência que não tem necessidade de entristecer a vida ou de fazer reinar a tristeza (DELEUZE, 1992). Uma aposta que recusa os desejos de tirania, autoritarismos com os quais muitas vezes nos deparamos nos serviços de saúde, pautados em modos verticalizados de gestão. Não buscou, por meio do processo formativo, uma verdade ou um ideal para o trabalho dos profissionais da rede básica de saúde. Privilegiamos a perspectiva de invenção de práticas aliançadas com processos que recusam enclausuramentos de todas as ordens.

Nossa intenção é que o relato das experiências vividas com os trabalhadores de saúde desse município se constitua como um movimento de resistência, na medida em que entendemos que criar outras formas de produzir saúde é resistir, libertar a vida que os humanos muitas vezes aprisionam. Partimos do pressuposto de que as estratégias de pura denúncia têm pouco alcance prático e pouco impacto conceitual. Em vez disso, buscamos levantar questôes que nos ajudem a avançar nas experiências de formação no campo da saúde. $\mathrm{O}$ objetivo deste 
artigo é, portanto, contribuir para que outras conexões possam ser feitas a partir

da experiência aqui relatada, estabelecendo, assim, um momento de produção, um momento de luta, pois, como nos indicou Santos (1989), dizer já é um início de vitória, mas não se diz o começo de uma luta.

\section{A PNH e os processos de formação}

A Política Nacional de Humanização no âmbito dos processos de formação parte de uma escolha ético-política consonante com suas diretrizes e princípios, que afirmam a impossibilidade de separar a gestão do cuidado/atenção e de produzir saúde, a não ser transversalizando práticas e saberes. A PNH opõe-se às políticas de formação que têm reproduzido a fragmentação dos saberes e práticas na área de saúde, políticas marcadas por assimetrias de saber e de poder, que fomentam um processo de produção de saúde reduzido ao binômio queixa-conduta:

Envolver-se com a produção do cuidado em saúde nos lança irremediavelmente no campo da complexidade das relaçôes, entre os sujeitos trabalhadores, gestores e usuários dos serviços de saúde, onde a opção excludente por um dos polos não se sustenta para a efetiva alteração dos modelos de atenção e gestão em saúde (HECKERT; NEVES, 2007, p. 145).

Nesse sentido, verifica-se que um dos desafios encontrados é colocar em análise os processos de formação que têm esvaziado os princípios do SUS, que dissociam atenção e gestão, pensamento e vida, e que ainda focalizam a intervenção profissional no binômio queixa-conduta (HECKERT; NEVES, 2007; PINHEIRO et al., 2005).

De acordo com Heckert e Neves (2007), um dos desafios enfrentados nas práticas de saúde relaciona-se aos modos verticalizados de gestão e na dissociação entre os modelos de atenção (modos de cuidar) e os modelos de gestão (modos de gestão). Esta cisão tem colaborado com práticas nas quais a gestão se reduz à administração do sistema de saúde e está centrada exclusivamente na figura do gestor. Desse modo, os gestores planejam e pensam a ordenação do sistema de saúde, e os trabalhadores executam e operacionalizam os planejamentos formulados por outros. Essa proposta indica modelos de gestão dicotômicos: de um lado, aqueles que planejam e pensam, e por outro, os que fazem e cuidam. As políticas de formação pautadas nesse modelo dualista instituem processos dissociados dos modos de cuidar e de gerir, e levam a uma cisão entre pensamento e vida: 
[...] entendemos que não se trata de apontar modelos político-pedagógicos ideais, abstratos e dissociados do cotidiano dos processos de trabalho, mas principalmente indicar modos de fazer a formação (princípios e métodos) que se construam num ethos da integralidade e da indissociabilidade entre cuidar, gerir e formar. Outrossim, requer entender a formação como "atitude" transdiciplinar, ou seja, em sua potência de produzir aberturas a novas sensibilidades, "dizibilidades" e visibilidades que expressam a multivetorialização nos quais estão envolvidas as práticas concretas de cuidado e gestão em saúde (HECKERT; NEVES, 2007, p. 148).

No modelo citado, a formação não é compreendida como uma aquisição de conhecimentos técnico-científicos voltados para uma categoria profissional a ser aplicada numa determinada realidade. A noção com a qual trabalhamos se contrapõe à de "instituição especialismos" que norteia muitos processos formativos. Tais práticas se baseiam na relação de tutela, quando pretendem autorizar o que é melhor ou pior para o outro; e potencializam hierarquizações, visto que seu funcionamento discrimina aquele que sabe e aquele que não sabe (HECKERT; NEVES, 2007).

O debate sobre a formação, no entanto, se encontra frequentemente atrelado à transmissão de conteúdos, e muitas vezes é compreendido como a transmissão de um conjunto de conhecimentos "verdadeiros", que pretende aproximar os trabalhadores dessa "verdade", para que então possam executar suas funções de forma eficaz. Esta perspectiva cientificista acaba por ocultar o caráter político social dos processos formativos, descartando tudo que não é autorizado pela "ideologia científica". Descarta experiências e construções cotidianas dos trabalhadores (BARROS; OLIVEIRA, 2004; BARROS, 2005).

Dessa forma, o viés de formação adotado reside menos em seu caráter de mera transmissão de conhecimento, ainda que não se prescinda do conhecimento. Visa-se ao afastamento de atividades formativas que produzam "fôrmas" e que reforcem, portanto, uma perspectiva bancária de produção e transmissão do saber, compreendida como processo cumulativo em que os saberes são depositados sequencialmente e cada conhecimento é hierarquicamente superior aos demais - produzindo, então, apenas a repetição do mesmo. Nos processos de formação, busca-se potencializar movimentos afirmadores de vida, que produzam contágio, e a desestabilização dos processos instituídos (BARROS, 2005; HECKERT; NEVES, 2007).

Nesse sentido, só é possível conceber uma formação que implique ações que se constituam num processo de construção coletiva com os sujeitos envolvidos. 
Entende-se que o movimento de mudança das práticas e da organização do trabalho só se tornará efetivo por meio da problematização dos modos de cuidar e de gerir instituídos, se estes movimentos estiverem conectados com as práticas de trabalho nos serviços de saúde, com seus trabalhadores e usuários (HECKERT; NEVES; 2007).

O processo de formação, portanto, é entendido como inseparável das condições concretas do trabalho:

A formação se dá como intervenções formadoras, isto é, todo o processo de forma-
ção é desde sempre situado, contingenciado pelas condições e meios do processo de
trabalho, condições e meios do trabalhador de viver no trabalho. Formar, portanto,
equivale a intervir na situação sempre coletiva do trabalho. Uma proposta de forma-
ção que não leve em conta as especificidades dos saberes e configuraçóes locais em
seu entrecruzamento estará fadada ao insucesso, pois nada transformará. Formação é
assim, trans-formação (BARROS; BENEVIDES, 2007, p. 78).

Ao entender o formar como um processo transformador, estamos estabelecendo uma relação indissociável entre o cuidado em saúde e os processos de gestão. $\mathrm{O}$ trabalhador de saúde é visto como protagonista de seu processo de trabalho, como alguém que planeja e executa, mesmo porque trabalhar é necessariamente gerir processos de trabalho, gerir modos de cuidar, e não apenas executar tarefas. Esta metodologia possibilita que os participantes assumam o papel de protagonistas e, a partir desta posição, possam extrair de suas vivências os elementos motivadores do estudo, ao mesmo tempo que se tornam capazes de intervir em suas realidades de trabalho, buscando construir soluçóes inovadoras para seus problemas cotidianos relacionados à gestão e à organização da rede de saúde. Desse modo, o que se deseja disparar são processos de "formação-intervenção" que incitem a produção de novas normas, novas formas de trabalho-vida.

Nesse contexto, temos trabalhado com um conceito de aprendizagem que segue algumas direções da autopoiese formulada por Maturana e Varela (1995) e da proposta de uma aprendizagem inventiva (KASTRUP, 1999) derivada dessa perspectiva. Tal conceito afirma uma concepção de aprendizagem que implica certa política e não tem sentido apenas psicopedagógico; é um processo de produção de subjetividade, um processo autopoiético, no qual Conhecer = Fazer = Ser se articulam de forma inexorável. O fazer é, portanto, ontológico.

Os processos de aprendizagem se efetivam na produção de breakdowns, ou seja, de quebras, de hesitações que precedem a ação e desmancham práticas cristalizadas. 
1092 O produto da aprendizagem não se identifica como uma repetição mecânica, mas como uma atividade criadora, de modo que a solução não esgota a problematização, nem a experimentação. Aprender é experimentar incessantemente e impedir que a aprendizagem forme hábitos cristalizados. Neste sentido, a aprendizagem não se reduz a um processo mental; ao contrário, é a resultante da experiência que se inscreve no corpo. Trata-se da corporificação da aprendizagem.

Outra importante inspiração para este estudo é o trabalho de Paulo Freire (1988). A perspectiva freireana considera que a aprendizagem só se efetiva quando tem sentido para o aprendiz - o que Freire denominou de aprendizagem significativa. O novo conhecimento precisa responder a uma pergunta e/ou ser construído a partir de um diálogo com o conhecimento já produzido, sempre criando, acumulando e renovando experiências. Impõe-se, portanto, a criação de dispositivos para que os trabalhadores se reúnam e discutam, reconhecendo que um processo de formação pautado nessa concepção de aprendizagem se compõe, necessariamente, com a reformulação da estrutura e do processo produtivo.

Então, como provocar mudanças das práticas? Vivendo o desconforto. Vivenciando e analisando práticas nos serviços de saúde. Criando novos modos de trabalhar, abrindo-se para o enfrentamento do desafio de produzir transformação e, portanto, não identificando os desafios como dificuldades incontornáveis. Ressaltamos a importância das experiências locais; da organização de ações em rede; das mudanças na gestão e nas práticas de atenção à saúde; do fortalecimento do controle social e da valorização dos saberes locais.

Impõe-se o reconhecimento de que o ato do trabalho é um ato pedagógico/ educativo, e nesse movimento em que produzimos nós mesmos e os outros, o processo é de incessante subjetivação. Nesta direção de análise, perseguese o pensamento crítico e inventivo que emerge da realidade experimentada cotidianamente, num processo constante de aprender aprendendo. Como nos indicou Paulo Freire (1988, p. 88): "A Educação tem caráter permanente. Não há seres educados e não educados. Estamos sempre nos educando".

O processo vivido no curso foi marcado por construções que iam se forjando no decorrer de seu desenvolvimento. Foi preciso entender que o padrão instituído de fazer e pensar no campo da saúde é insuficiente ou insatisfatório para dar conta dos desafios do trabalho. Como nos indicou Canguilhem (2000), o meio é sempre infiel, imprevisível, marcado pela variabilidade. Foi nesta direção que 
se construiu o curso de Formação de Apoiadores/Multiplicadores da PNH

no âmbito da atenção básica em um município do Estado do Rio de Janeiro, afirmando-se como uma estratégia do Sistema Único de Saúde (SUS) para a transformação das práticas de formação, de atenção, de gestão e de participação popular. Esta estratégia parte do pressuposto de que os serviços de saúde são organizações complexas, ou seja, sistemas inventivos, marcados por um funcionamento imprevisível e criador. Somente a reflexão crítica das práticas reais pode viabilizar a adesão dos trabalhadores aos processos de mudança do/no cotidiano, como indicam as diretrizes do SUS: descentralização, universalidade, equidade, integralidade e participação popular.

\section{Os cursos da Política Nacional de Humanização}

Ao oferecer cursos de formação, a Política Nacional de Humanização da Atenção e da Gestão (PNH) tem como objetivo promover e sistematizar ações de formação e pesquisa. Sua proposta é que sejam produzidas e fomentadas redes capazes de ampliar os graus de transversalidade da $\mathrm{PNH}$ como política pública, buscando conquistar a capilarização da humanização das práticas em saúde por meio da formação de multiplicadores. Assim, os processos de formação dirigemse para um público-alvo selecionado, atores que são considerados estratégicos e envolvidos com os diferentes processos de produção de saúde, agentes potenciais para o trabalho de multiplicação, ampliação e de sustentação da Política de Humanização do SUS (PNH, 2008).

Santos Filho (2009) pontua que os cursos de formação da PNH têm como proposta formar profissionais de saúde que possam desenvolver a capacidade de análise, fomento e consolidação de mudanças na gestão e nos modos de atenção à saúde. $\mathrm{O}$ processo de formação tem como base práticas concretas de intervenção, em que os referenciais da $\mathrm{PNH}$ seriam operacionalizados no sentido de produzir práticas coletivas entre os diferentes atores do SUS: usuários, trabalhadores e gestores. Nesse sentido, os cursos de formação da PNH se valem da noção de apoio institucional (CAMPOS, 2000). Os apoiadores teriam uma dupla função ao atravessar o processo de trabalho dos coletivos: ajudar nas tarefas de qualificar as ofertas clínicas e de saúde pública, assim como de ampliar o grau de grupalidade. 
A função apoio é uma metodologia de gestão da atenção que modifica a tradição dos sistemas hierarquizados. Ela procura ativar e construir espaços de comunicação intensa e o compartilhamento de conhecimentos e saberes (CAMPOS; DOMITTI, 2007). O apoio atua na cogestão dos espaços coletivos e opera com um conhecimento que oferece às equipes suporte especializado, viabilizando, deste modo, o trabalho. A função apoio, portanto, se constitui como estratégia, que se expressa num determinado modo de fazer, que não está localizado numa pessoa, mas que dá passagem a outros modos de trabalhar, fortalece e monta redes de coletivos. Lugar, paradoxalmente um não-lugar, que instiga, viabiliza processos de desestabilização, faz surgir outros planos de afetos: a constituição de redes de conversa e redes afetivas.

Ao desnaturalizar alguns saberes que insistem em desistoricizar nossas práticas e tirar-lhes as máscaras do tempo, fazer apoio é falar com eles (trabalhadores), e não falar por eles, a respeito do trabalho que desenvolvem.

O objetivo de um apoiador, portanto, seria prestar apoio nos processos de mudança das organizações, articulando conceitos e tecnologias advindas da análise institucional e da gestão. Em síntese, a tarefa primordial do apoio seria oferecer suporte ao movimento de mudança deflagrado por coletivos, buscando fortalecê-los. Nas palavras de Benevides de Barros (1994, p. 14):

O apoiador não é simplesmente um consultor, que palpita sobre o trabalho e diz das mazelas do grupo; nem tampouco sua ação se resume à assessoria, indicando caminhos a partir de um suposto saber externo que atua sobre o grupo. Sem negar estas especificidades, o apoiador é alguém que penetra no grupo para acioná-lo como dispositivo, se apresentando como um "fora dentro incluído", alguém que atravessa o grupo não para feri-lo, ou para anunciar suas debilidades, mas para operar junto com o grupo em um processo de transformação na própria grupalidade e nos modos de organizar o trabalho e de ofertar ações e estratégias de saúde.

Desse modo, os cursos visam a formar apoiadores institucionais capazes de fomentar rede no SUS, promover mudança nos modos de gestão dos serviços e processos de trabalho em saúde, tomando por referência a Política Nacional de Humanização da Gestão e da Atenção à Saúde. Apoiadores que poderão multiplicar os modos de fazer preconizados pela $\mathrm{PNH}$. Mas quem são esses apoiadores-multiplicadores e o que os processos de formação pretendem formar? Profissionais da saúde que vão coordenar outros processos de formação. Multiplicação de quê? Da capacidade de fomentar redes de atenção à saúde, de 
analisar os processos de trabalho em curso nos serviços, de formular questôes que façam deslocar o que está instituído e de inventar estratégias para mudar situações desfavorecedoras dos processos de produção e promoção de saúde. Multiplicação de quem? De companheiros que também possam analisar o que está acontecendo e formular propostas de alteração das situações que vão na contramão das formas verticalizadas de gestão do trabalho. De aliados na tarefa de construir rodas de conversa e implementar a cogestão nas unidades.

Com esse propósito, construímos um plano de curso visando à criação de redes aquecidas, que proliferam, produzem dessubjetivação e se abrem para formas de trabalhar que desejam o múltiplo e não temem a dissolução das formas instituídas. O projeto foi construído partindo da experimentação, criando fissuras, dando vazão à virtualidade.

Então, o que este curso pretende atingir? Qual sua potência? Buscávamos instituir algo que não fosse estanque, pontual, mas um processo contínuo de diálogos, um confronto crítico entre as diferentes especialidades. O trabalho coletivo seria o foco deste curso que privilegia a escuta e o olhar diferenciado que duvida do olhar "natural". Segundo Athayde et al (2003), desenvolvemos um curso com um sentido semelhante daquele quando nos referimos ao curso de um rio: um fluxo, uma corrente, forças diversas que buscam seguir juntos seus caminhos, afirmando no movimento seu modo de ser na vida, e assim colaborando para a afirmação da vida neste planeta.

O que nos interessava, portanto, não era a realização de um curso cujo modelo seria definido a priori, uma vez que sua potência dependeria da qualidade dos encontros que conseguiríamos lograr. Rastreamos linhas tênues para conhecer o movimento da rede básica de saúde do município, que ora abre portas, ora tranca portas e procura instalar-se nesses interstícios para não sucumbir aos maniqueísmos e/ou fatalismos (LAVRADOR, 2006). Apostamos na invenção, na possibilidade de esses trabalhadores estarem cotidianamente inventando-se e inventando mundos. Indagamos processos que produzem um lugar para esses trabalhadores e os movimentos políticos que os instituem, mudando o foco dos sujeitos - trabalhadores, gestores e usuários - para a produção das práticas. Um curso-dispositivo, portanto, uma vez que ao negar os especialismos, afirma que ninguém pode ser competente pelo outro. 


\section{A Atenção Básica e a Política Nacional de Humanização}

Os primeiros movimentos para a montagem do curso para formar apoiadores/ multiplicadores da PNH no âmbito da atenção básica no município ocorreram em dezembro de 2007, quando foi realizada a primeira reunião entre a coordenação da Política Nacional de Humanização do Estado do Rio de Janeiro e representantes da Secretaria Municipal de Saúde do município em questão. Foram iniciadas nesse encontro as pactuações para a efetuação de um projeto de formação voltado para o incremento da Estratégia de Saúde da Família. O município, apesar de ter avançado em muitas áreas da saúde, identificava a necessidade do fortalecimento do vínculo entre profissionais da saúde e usuários, para um atendimento mais próximo do preconizado pelo SUS no que se refere à integralidade, equidade e universalidade. $\mathrm{O}$ modelo hospitalocêntrico atuava ainda de forma hegemônica em boa parte das práticas dos profissionais e usuários, dificultando as relações e a efetivação de processos de promoção, prevenção e recuperação em saúde.

No município, cuja população residente é estimada em 105 mil habitantes, encontram-se implantadas 13 equipes de Saúde da Família, com aproximadamente 32 mil habitantes cadastrados, 72 agentes comunitários de saúde, 13 médicos, 13 enfermeiros e 13 técnicos de enfermagem, num total que abrange $32 \%$ da população geral. A equipe multiprofissional de saúde para supervisão e implantação de educação permanente trabalha com uma carga horária semanal de 20 horas e é composta por: pediatra, ginecologista, clínico geral, assistente social, nutricionista, enfermeiro e psicólogo. A referência para consultas especializadas é a unidade ambulatorial do hospital municipal, que oferece atendimento nas áreas de proctologia, urologia, ortopedia, oftalmologia, otorrinolaringologia, psiquiatria, psicologia, fonaudiologia, fisioterapia, cirurgia bucomaxilofacial, cirurgia geral, cirurgia ginecológica, cardiologia, neurologia, dermatologia, nutrição, reumatologia, angiologia e endocrinologia.

A expansão e a qualificação da atenção básica, organizadas pela Estratégia Saúde da Família, compõem parte do conjunto de prioridades políticas apresentadas pelo Ministério da Saúde e aprovadas pelo Conselho Nacional de Saúde. Esta concepção supera a antiga proposição de caráter exclusivamente centrado na doença; o processo se dá por meio de práticas gerenciais e sanitárias, democráticas e participativas, sob a forma de trabalho em equipes, dirigidas às populações de territórios delimitados, pelos quais assumem responsabilidade. Mediante a 
adstrição de clientela, as equipes de Saúde da Família estabelecem vínculo com a população, possibilitando o compromisso e a corresponsabilidade dos profissionais com os usuários e a comunidade. Seu desafio é ampliar a área de atuação, visando a maior resolubilidade da atenção, na qual a Saúde da Família é compreendida como a estratégia principal para mudança desse modelo, que deverá sempre se integrar a todo o contexto de reorganização do sistema de saúde.

A atenção básica, como nos indica Merhy (1997), diferentemente do hospital, possibilita menor aprisionamento de suas práticas a um processo de trabalho médico restrito, ou mesmo circunscrito no tempo, podendo abrir-se às mais diversas alternativas de formas de ações em saúde. É importante deixar claro, no entanto, que a noção de rede básica não deve se confundir com um espaço físico, visto que pressupõe um espaço de trabalho em saúde. Ainda segundo Merhy (2005), a militância na saúde age na reconstrução dos fazeres, na remontagem das práticas, na composição dos saberes, que se cria na imanência do viver; desmanchando territórios de produção de certezas prescritivas.

A Saúde da Família, como estratégia estruturante dos sistemas municipais de saúde, tem provocado importante movimento com o intuito de reordenar o modelo de atenção no SUS. Essa estratégia busca maior racionalidade na utilização dos demais níveis assistenciais e tem produzido resultados positivos nos principais indicadores de saúde das populações assistidas às Equipes de Saúde da Família. Para que sejam cada vez mais efetivas e eficazes suas ações, é necessária uma atenção especial, voltada para a formação dos profissionais envolvidos na prática do cuidado. Segundo Campos (2005), para atingir a capacidade de resolver 80\% dos problemas de saúde, a atenção básica deverá ordenar-se segundo algumas diretrizes: trabalho em equipe interdisciplinar; responsabilidade sanitária por um território e construção de vínculo entre equipe e usuário; abordagem do sujeito, da família e de seu contexto (busca da integralidade); reformulação do saber e da prática tradicional em saúde; e articular a atenção básica em uma rede de serviços de saúde que assegure apoio e amplie a capacidade de resolver problemas em saúde. Para esse autor, apesar das mudanças de cenário, a atenção básica em saúde tende a reproduzir o modelo biomédico dominante, sendo necessários esforços sistemáticos e continuados para reformular esse tipo de prática e de saber.

A Política Nacional de Humanização, conforme já explicitado, tem por objetivo central qualificar a gestão e a atenção à saúde, ou seja, é uma política que induz inovações nas práticas gerenciais e nas práticas de saúde, colocando 
para os diferentes coletivos/equipes implicados nestas práticas o desafio de superar limites e experimentar novas formas de organização dos serviços e novos modos de produção e circulação de poder. A aposta desta política, ao afirmar a inseparabilidade entre gestão e atenção, entende que a gestão dos processos de trabalho em saúde não pode ser compreendida como tarefa administrativa separada das práticas de cuidado. Neste sentido, vem produzindo um cardápio de ofertas-dispositivos para o desafio da construção de uma rede de cuidado territorial que responda às necessidades de usuários e trabalhadores de saúde.

Essa inovação é complexa e exige, de um lado, vontade política, e de outro, capacidade de realização de mudanças. A Política Nacional de Humanização, com seus princípios, diretrizes e metodologias, colabora e presta suporte para que os coletivos alterem seus processos de trabalho, tornando-os mais democráticos e inventivos, ampliando a capacidade de acolher e resolver necessidades de saúde, reconhecendo e atribuindo valor social, valor de uso, de bem comum, às ações dos trabalhadores da saúde. Dessa forma, contribui tanto para a implantação de processos de mudança, quanto para sua sustentabilidade.

O curso, proposto em parceria com a Secretaria Municipal de Saúde do município em questão, se inseriu na perspectiva de qualificar e potencializar ações e estratégias da Política Nacional de Humanização, cujos objetivos, entre outros, são ampliar e qualificar o acesso, a participação social, o acolhimento e a gestão dos serviços prestados no SUS.

\section{O curso no município}

O curso se organizou a partir de dois eixos: os momentos de concentração (encontros com todos os participantes) e os momentos de dispersão (atividades realizadas pelos participantes em seus respectivos serviços). Essas estratégias metodológicas serviram como pontos de partida para abrigar/disparar a articulação de/em rede. Chamamos esse processo de alternância.

Os momentos de concentração foram realizados respeitando-se uma programação estruturada previamente e contaram com a participação de consultores / "professores" convidados segundo os temas priorizados, havendo um desenho específico para cada um destes encontros em função da especificidade de cada tema. Os momentos de concentração ocorreram ao longo de sete encontros quinzenais, com duração de oito horas por encontro, num espaço que comportava, 
prioritariamente, o trabalho em roda. As temáticas abordadas nos encontros

presenciais eram relacionadas aos princípios, diretrizes e dispositivos da Política Nacional de Humanização (BRASIL, 2008). Os temas trabalhados foram: SUS e rede; princípios, diretrizes e dispositivos da PNH; acompanhamento avaliativo na PNH; clínica ampliada; acolhimento; saúde do trabalhador e processo de formação; direito dos usuários e apresentação de linhas de ação nos serviços.

Os momentos de dispersão foram organizados por meio de atividades propostas pelos consultores / "professores", que funcionavam como facilitadores do processo, e acordadas com os trabalhadores nos momentos presenciais, realizadas pelos participantes junto com outros profissionais de seus respectivos serviços. Essas atividades não ocorreram a partir de uma estrutura rígida. Os grupos puderam se encontrar para as atividades de dispersão, de acordo com a disponibilidade de seus membros.

A seleção dos participantes ficou a cargo da Coordenação do Programa de Saúde da Família do município, que identificou os trabalhadores que teriam um perfil multiplicador e de disseminação de algumas propostas da PNH nos serviços. Neste processo houve a intenção de que o grupo fosse composto de modo heterogêneo, tanto em relação à especialidade dos participantes, quanto em suas inserçôes nos serviços e na estrutura gestora do município. Para garantir a heterogeneidade dos participantes, foi formado um grupo com médicos, enfermeiros, técnicos de enfermagem, dentistas e agentes comunitários - pertencentes às 13 unidades de PSF do município - além de algumas pessoas ligadas à gestão. Não foi possível garantir, entretanto, a participação de trabalhadores ligados aos hospitais, uma vez que os profissionais da única unidade hospitalar no município compareceram a apenas alguns encontros presenciais e não deram prosseguimento à atividade. Este fato dificultou a discussão entre a atenção básica e a rede hospitalar, que pretendia tornar o espaço do curso um fórum de análise de cenário e de construção de reflexões e propostas em conjunto para o tema.

Cada unidade de saúde foi representada por dois ou três profissionais. O fato de haver uma diversidade de profissionais, mantendo uma representatividade mínima de cada unidade, possibilitou a experimentação, por parte dos trabalhadores, de uma dimensão coletiva inerente aos processos de trabalho. $\mathrm{O}$ curso ocorreu no período de junho a setembro de 2008, no próprio município, em uma sala cedida pela prefeitura. Contou com 40 participantes, gestores e trabalhadores de nível 
1100 médio e superior, ligados à atenção básica, oriundos da Estratégia de Saúde da Família e de unidades de saúde.

Procuramos inicialmente mapear os problemas encontrados nos processos de trabalho dos serviços de saúde nos quais os participantes estavam inseridos. O mapeamento funcionou como um analisador que permitiu dar visibilidade a várias questōes que constituem as políticas públicas no Brasil: falta de vínculo empregatício dos trabalhadores, deficiência na estrutura física dos serviços, baixos salários, dificuldade em efetuar o processo de referência e contrarreferência, rede enfraquecida, dificuldade de interação entre as equipes, relações conflituosas com os usuários, falta de recursos necessários para a realização do trabalho e desconhecimento da PNH.

A partir desse levantamento, iniciou-se um processo de reflexão-análise das questôes levantadas pelo grupo. Observamos, por um lado, que os trabalhadores estavam sofrendo em decorrência das precárias condições de trabalho características da saúde pública de nosso país, mas, sobretudo, estavam muito preocupados com a manutenção de seus contratos, por causa da proximidade das eleiçôes municipais e consequente mudança de governo que os havia empregado. Por outro lado, expressava-se uma passividade frente aos desafios a serem enfrentados, por meio de posturas queixosas, que não acreditavam na mudança das situações de trabalho, e uma culpabilização dos gestores, dos usuários e de alguns "maus profissionais". Pareciam não "ter nada a ver com o vivido", num processo de alheamento preocupante. Era preciso convocá-los para um processo de análise de suas implicações.

No decorrer do processo, foi problematizado um saber-fazer dos trabalhadores e estes foram convocados a criar estratégias de intervenção frente aos desafios colocados nos sistemas e serviços de saúde. Visávamos a que o grupo assumisse seu protagonismo e sua corresponsabilização em seus processos de trabalho.

As atividades de dispersão relacionadas ao "trabalho em equipe", "acesso aos serviços" e "clínica ampliada", realizadas entre os participantes e os trabalhadores de seus respectivos serviços, permitiram o debate do cotidiano de trabalho no SUS, os impasses vivenciados no dia a dia e a criação de estratégias coletivas para a superação dessas dificuldades. Ao mesmo tempo, a apresentação das atividades de dispersão nos encontros presenciais materializava o método de inclusão da $\mathrm{PNH}$ : trabalhar com as práticas concretas dos trabalhadores, onde era possível 
ouvir e trocar experiências de reivenção do SUS, incluindo os conflitos, as relações de poder e os movimentos sociais que povoam o entorno dos serviços. Esse duplo movimento estimulava a construção de redes "para dentro" (entre os trabalhadores em seus serviços) e redes "para fora" (entre os trabalhadores dos diferentes serviços). As redes "de dentro" começaram a se aquecer por meio da sistematização de reuniōes de equipe, que até então não ocorriam ou ocorriam de forma esporádica. Por sua vez, as redes "de fora" foram se fortalecendo durante o processo, e o dispositivo-curso foi-se constituindo como um espaço sistemático de problematização e comunicação entre os diferentes serviços de atenção básica do município.

O processo formativo foi marcado por movimentos que se intercalavam entre o desânimo e a mobilização, a passividade e a luta. Foi possível criar um espaço que pôde acolher ao mesmo tempo manifestações ora mais centradas "em dificuldades", ora sinalizando saídas, demonstrando possibilidades, criando possíveis. Viabilizaram-se, assim, o resgate das experiências, a análise das implicações dos sujeitos nestas experiências e dos rumos que se pode dar a elas.

Como ilustração desse movimento, trazemos a fala de uma trabalhadora de saúde, dentista, que num primeiro momento disse que achava a proposta da $\mathrm{PNH}$ muito bonita, mas que o problema do acesso nas unidades de saúde era insolúvel, porque o ser humano é egoísta, mente para conseguir uma consulta que muitas vezes não requer urgência, como por exemplo, a limpeza de um tártaro. Num segundo momento, a dentista relatou que após o encontro presencial em que foi debatido o tema "acolhimento", ela conversou com a equipe de sua unidade sobre o problema do acesso do usuário ao serviço e se deu conta de que, ao apontar um dedo para acusar o usuário, tinha outros quatro dedos apontados para si. Pode compreender, desse modo, que era importante que a equipe pensasse em estratégias coletivas para a resolução do problema do acesso naquela unidade.

Depois dessa primeira fase do processo, os participantes tiveram como atividade de dispersão construir um planejamento de intervenção para seus serviços. Como se tratou de um curso compactado, de apenas três meses, optouse não por um "planejamento" detalhado, mas por algumas linhas de ação que esperavam implementar em seus serviços.

O debate sobre as linhas de ação formuladas permitiu-nos perceber que a proposta do curso e seu modo de funcionamento viabilizaram maior aproximação 
1102 dos princípios, diretrizes e dispositivos da $\mathrm{PNH}$, assim como a identificação de intervençôes disparadas pelos apoiadores nos seus serviços. Podemos destacar as açōes de cogestão, em forma de reuniōes com os usuários para o compartilhamento de decisões relativas ao serviço; de acolhimento, com implantação de intervençõos que garantam o acesso do usuário ao serviço; de clínica ampliada, com as discussóes em equipe dos casos clínicos; e de saúde do trabalhador, na medida em que as equipes começaram a discutir e repensar seus processos de trabalho. Desse modo, podemos constatar que a construção de linhas de ação norteadoras para as possíveis intervenções disparam rodas de conversa nos serviços, desestabilizando os modos de gestão e atenção instituídos (HECKERT; NEVES, 2007).

$\mathrm{Na}$ roda de avaliação, ao fim do curso, muitos participantes relataram e expressaram mudanças subjetivas significativas, sentindo-se mais "potencializados" e "vivos"; outros disseram que o curso proporcionou uma "abertura para novas possibilidades". Foram experimentadas mudanças afetivas, ampliação dos graus de comunicação - em alguns casos, restritos a expressões dos sujeitos; em outros, repercutindo nos processos de trabalho dos serviços de saúde. Muitas unidades, que não realizavam reuniōes de equipe sistemáticas ou não entendiam a função gestora e organizativa das mesmas, passaram a lidar com este dispositivo de outra forma, em decorrência da inserção de alguns de seus profissionais no curso de formação.

A escolha inicial de constituir um grupo de participantes heterogêneo mostrouse bastante acertada. Ao longo dos encontros presenciais, as rodas de conversa, os pequenos grupos ou a grande roda tornaram-se palco de exercício da democracia discursiva e de trabalho de construção de consensos coletivos, a partir da inclusão das tensões e dos dissensos como próprios do processo. Estes momentos foram muito ricos, embora fosse nítida a participação desigual dos participantes, havendo aqueles que se colocavam mais e outros que se restringiam a acompanhar as conversas. Uma estratégia importante para minimizar esse tipo de problema, aumentando a convocação à fala de todos os participantes, foi ter incluído na metodologia dos encontros presenciais momentos de trabalhos em pequenos grupos.

Poder compartilhar as diferenças durante as rodas de conversa mostrou-se uma poderosa estratégia de sensibilização para a construção de análises compartilhadas dos campos problemáticos vivenciados. Muitos sinalizaram que a experiência foi importante para o entendimento da importância das trocas entre os profissionais e da afirmação da multiplicidade inerente aos humanos - logo, entre as especialidades. 
Esse movimento disparado no curso acabou qualificando as reuniōes de equipe já existentes em alguns serviços e encorajando sua realização em outras unidades.

As avaliaçôes feitas pelos participantes do curso nos permitiram reafirmar as conclusōes de Heckert e Neves sobre os resultados obtidos no Curso de Formação de Apoiadores da Política Nacional de Humanização da Atenção e Gestão do SUS no ano de 2006:

\begin{abstract}
Essa ação (o curso) se constituiu como oportunidade de problematização da experiência de trabalho vivenciadas pelos profissionais da saúde, uma vez que privilegiou o compartilhamento de experiências entre esses atores, e destes com os profissionais de saúde atuantes nos sistemas/ serviços em que as intervenções se deram, e os usuários do SUS (HECKERT; NEVES, 2007, p. 157).
\end{abstract}

Constatamos ainda que o curso funcionou como um dispositivo incitador da grupalidade e da agregação, produzindo desse modo o aquecimento de redes entre os trabalhadores nos seus serviços e no sistema local de saúde, possibilitando, ainda, colocar em pauta a discussão sobre a humanização das ações em saúde (HECKERT; NEVES, 2007). Um dos maiores indicadores do que estamos afirmando foi a instituição, a partir de uma linha de ação proposta pelo grupo, do Fórum Permanente de Humanização da Atenção Básica, com encontros bimensais. Esse fórum tem sido um espaço de discussão sobre os processos de trabalho nas diferentes unidades de atenção básica do município, onde os trabalhadores de saúde e gestores são protagonistas, problematizando suas práticas concretas e criando estratégias coletivas para a superação dos desafios cotidianos. Sua metodologia acompanha os preceitos do modo de fazer da $\mathrm{PNH}$, que aposta no método da tríplice inclusão, o qual envolve três vetores do cuidado: os sujeitos (gestores, trabalhadores, usuários), os coletivos (movimento sociais e movimentos de trabalhadores sensíveis) e os analisadores sociais (aspectos que colocam nossa prática em análise, problematizando-a).

Para garantir a inclusão dos sujeitos, aposta-se no "fazer roda", uma prática de lateralização que pretende que a comunicação se ponha a rodar. Acredita-se que o aquecimento da roda, facilitando e provocando a comunicação em grupo, provoca uma desestabilização da forma tradicional como a comunicação vem-se realizando. Em uma instituição podemos encontrar, comumente, dois eixos de organização da comunicação: a comunicação entre os diferentes na instituição - comunicação vertical, de obediência; e a comunicação entre os iguais - comunicação horizontal, corporativa. Para uma aposta nas mudanças das práticas, é necessário um 
terceiro eixo: o da transversalidade, eixo de uma comunicação lateralizada entre os diferentes setores e especialidades. Ou seja, o aumento do grau de abertura de comunicação nos grupos e entre os grupos. Desse modo, o fórum se constitui como um dispositivo que provoca transversalização nos modos de se comunicar, possibilitando o aparecimento e a inclusão na roda de comunicação dos pontos críticos e tensionamentos. Provoca, assim, a construção de novos modos de se relacionar e de gerir o trabalho entre trabalhadores e gestores.

\section{Algumas questôes finais}

Entendemos que na formação de apoiadores/multiplicadores da $\mathrm{PNH}$ no âmbito da atenção básica realizado no município do Estado do Rio de Janeiro, reafirmamos o modo de fazer dessa política, pautado num método que aposta em práticas de formação conectadas ao processo de trabalho, e que funcionam como dispositivos de intervenção nas práticas de produção de saúde. Tal estratégia afirma as redes de serviços como espaços de sociabilidade, de trocas, em que se enfatiza a produção de saúde como produção de subjetividades, colocando em questão práticas disciplinares.

O dispositivo curso viabilizou acionar coletivos como plano relacional, de coengendramento, de produção de subjetividades (ESCÓSSIA; KASTRUP, 2005). Buscou romper com os modelos corporativo-centrados, ou seja, modos de funcionamento pautados nos núcleos profissionais que consideram o cuidado apropriado a um discurso particular e próprio de cada núcleo profissional (MERHY, 2005). O alcance das nossas intervençōes se expressa por meio de uma constante mudança nos posicionamentos que ocupamos como trabalhadores.

A aposta foi, assim, em mudanças que não se reduzem à realidade das condições dadas a priori, mas em transformação que se efetiva num plano que é também de intensidades, de encontros entre os sujeitos e as várias formas de compor a vida, habitando um espaço não apenas geográfico, mas também subjetivo. A cidade subjetiva (FONSECA, 2003) nos revela o urbano como fonte de encontros entre as pessoas e os elementos que compõem a sociedade, dos quais derivam as mais variadas produções de existência e se intensifica o plano de efetuação de novos modos de subjetivação. É na multiplicidade dos encontros que criamos possíveis modos de existir. Modos que se constituem como produtos da atuação de linhas do cotidiano, que fazem a diferença e acionam processos de singularização. 
Visou-se a articular saberes e práticas, o que presume uma análise constante dos processos de homogeneização construídos pela soberania dos especialismos que têm produzido formas de cuidado. Em muitas ocasiōes, os trabalhadores falavam da dificuldade que as equipes de saúde têm para dialogar e problematizar como trabalham e as articulações entre as especialidades. Referiam-se à dificuldade de criar espaços onde o que se discute ou se privilegia são os processos de trabalho, e não a doença descontextualizada; esquecendo-se de que os sujeitos são históricos, as demandas, portanto, mudam no tempo, estão atravessadas por valores, que também trazem as marcas do tempo.

O intuito foi, outrossim, considerar a co-construção de autonomia como uma das finalidades do trabalho em saúde, o que tem importantes implicaçōes políticas e organizacionais. Adotar essa diretriz no âmbito das políticas de saúde exige uma reformulação radical nos valores ético-políticos que têm sustentado tais políticas e isso não se faz se não produzimos uma torção nos modelos de gestão e nas práticas em saúde, incluindo o próprio conceito do que é produzir saúde. O desafio foi co-construir a capacidade de reflexão-crítica e de ação autônoma para todos os evolvidos nos processos. Há pouca explicitação ou contratação sobre o que caberia decidir a cada nível hierárquico da administração, e isso gera não poucos atritos, equívocos. Essas tendências dificultam a constituição de autonomia dos agentes.

Autonomia, como nos indicam Onoko e Campos (2006), não é um estado estático, mas um processo dinâmico que não se desvincula dos modos de gestão instituídos historicamente. Logo, não é o contrário de dependência, nem a independência total que leva a individualismos e à privatização das práticas, mas um processo que estimula a capacidade de os sujeitos lidarem com sua rede de dependências, de co-constituição de maior compreensão, de análise e de ação conforme objetivos democraticamente estabelecidos nas equipes. Falar em autonomia é falar, necessariamente, em co-constituição, coprodução de práticas, cogestão nos serviços, o que implica, ainda, responsabilidade, corresponsabilidade.

Ainda com Onocko e Campos (2006), afirmamos que as relaçôes de gestão muitas vezes escamoteiam a produção de autonomia e escondem certo autoritarismo heteronímico. Decisões políticas e técnicas são dadas como verdade e impostas aos trabalhadores como se fossem regras divinas e não definições de uma determinada administração. 
Um frágil sistema de cogestão e de avaliação dos processos de trabalho, ao centrar toda a "culpa" pelo mau funcionamento na competência ou incompetência dos trabalhadores, não fortalece a autonomia e o protagonismo na produção de saúde. Num processo de cogestão e coprodução de sujeitos e mundos, não seria legítimo poupar os diferentes segmentos de análises de implicação, ou seja, da análise de sua responsabilidade sobre a situação experimentada. Desresponsabilizar-se dos modos de funcionamento em curso nos estabelecimentos já é uma posição política. Mas o que afirma tal posição? Que valores produz? Os trabalhadores sempre constroem caminhos que viabilizam a intervenção no instituído, ainda que, na maioria das vezes, busca-se condená-los a aceitar de forma silenciosa mudanças e diretrizes formuladas ao compasso da economia de recursos e impostos por uma política econômica que não favorece políticas públicas no sentido que apontamos na PNH. Poder discutir em prol da autonomia, afirmar práticas cogestivas exige deliberação, protagonismo e análise dos efeitos de nossas práticas quanto à produção de saúde.

\section{Referências}

ATHAYDE, M.R.C.; BRITO, J.; NEVES, M. (Org.). Caderno de método e procedimentos: Programa de formação em saúde, gênero e trabalho nas escolas. João Pessoa: Editora Universitária UFPB, 2003.

BARROS, M. E. B. Desafios ético-políticos para a formação dos profissionais de saúde: transdiciplinaridade e integralidade. In: PINHEIRO, R.; MATTOS, R.A (Org.). Ensinar saúde: a integralidade e o SUS nos cursos de graduação na área da saúde. Rio de Janeiro: Cepesc, 2005. p. 131-150.

BARROS, M.E.B.; BENEVIDES, R. A potência formativa do trabalho em saúde. In: PINHEIRO, R.; MATTOS, R.A.; BARROS, M.E.B. (Org.). Trabalho em equipe sob o eixo da integralidade: valores, saberes e práticas. Rio de Janeiro: Cepesc, 2007. p. 75-84.

BARROS, M.E.B.; OLIVEIRA, S.P. A psicologia na intercessão saúde e trabalho: experiência numa escola pública de Vitória. Cadernos de Pesquisa em Educação PPGE-UFES, Vitória, v. 10, n. 19 p. $82-113,2004$.

BENEVIDES, R.; PASSOS, E. A humanização como dimensão pública das políticas de saúde.Revista Ciência e Saúde Coletiva, Rio de Janeiro, v. 10, n. 3, p. 561-571, 2005a.

. Humanização na saúde: um novo modismo? Interface - Comunicação, Saúde, Educação, São Paulo, v. 9, n. 17, p. 389-394, 2005 b. 
BRASIL. MINISTÉRIO DA SAÚDE. HumanizaSUS: Documento base para gestores e trabalhadores do SUS. Brasília: Ministério da Saúde, 2008.

CAMPOS, G.W.S. Um método para análise e cogestão de coletivos: a construção do sujeito, a produção de valor de uso e a democracia em instituiçôes: o Método da Roda. São Paulo: Hucitec, 2000.

. Papel da rede de atenção básica em saúde na formação médica - Diretrizes. Documento preliminar. Revista da Associação Brasileira de Educação Médica. Disponível em www. abem-educmed.org.br/pdf/doc. Rio de Janeiro, 2005. Acesso em: 28 maio 2008.

CAMPOS, G.W.S.; DOMITTI, A.C. Apoio matricial e equipe de referência: uma metodologia para gestão do trabalho interdisciplinar em saúde. Cadernos de Saúde Pública, Rio de Janeiro, v. 23, n. 2, p. 399-407, fev. 2007.

CANGUILHEM, G. O normal e o patológico. Rio de Janeiro: Forense Universitária, 2000.

DELEUZE, G. Conversaçôes. Rio de Janeiro: Ed 34, 1992.

FONSECA, T.G. Cidade Subjetiva. In: FONSECA, T. G. et al. Cartografias e devires. Porto Alegre: UFRGS, 2003. p. 253 - 258.

HECKERT, A.L.C.; NEVES, C.A.B.N. Modos de formar e modos de intervir: quando a formação se faz potência de produção de coletivo. In: PINHEIRO, R.; MATTOS, R.A.; BARROS, M.E.B (Org.). Trabalho em equipe sob o eixo da integralidade: valores, saberes e práticas. Rio de Janeiro: Cepesc, 2007. p. 145-160.

ESCÓSSIA, L.; KASTRUP, V. O conceito de coletivo como superação da dicotomia indivíduo-sociedade. Psicologia em Estudo, Maringá, v. 10, n. 2, p. 295-304, 2005.

FREIRE, Paulo. Pedagogia da esperança: um reencontro com a pedagogia do oprimido. Rio de Janeiro: Paz e Terra, 1998.

KASTRUP, V. A invenção de si e do mundo: uma introdução do tempo e do coletivo no estudo da cognição. Campinas: Papirus, 1999.

LAVRADOR, M.C.C. Loucura e vida na contemporaneidade. Tese (Doutorado em Psicologia) - Universidade Federal do Espírito Santo, Vitória, 2006.

MATURANA, H.; VARELA, F. A árvore do conhecimento: as bases biológicas do entendimento humano. São Paulo: Editorial Psy, 1995.

MERHY, E. A rede básica como uma construção de saúde pública e seus dilemas. In: MERHY, E; ONOCKO-CAMPOS, R. (Org.). Agir em saúde, um desafio para o público. São Paulo, Hucitec, 1997.

MERHY, E. Engravidando palavras: o caso da integralidade. In: PINHEIRO, R.; MATTOS, R. A. (Org.). Construção social da demanda: direito à saúde, trabalho em equipe, participação e espaços públicos. Rio de Janeiro: Cepesc, 2005. p. 195-206. 
PINHEIRO, R. et al. A integralidade na prática da formação e no cuidado em saúde. In: CONGRESSO NACIONAL DA REDE UNIDA, 6. Belo Horizonte, Anais... 2005.

ONOCKO-CAMPOS, R. T.; CAMPOS, G.W.S. Co-construção de autonomia: O sujeito em questão. In: CAMPOS, et al. (Org.). Tratado de Saúde Coletiva. São Paulo: Hucitec, 2006.

SANTOS, L. G. Tempo de ensaio. São Paulo: Companhia das Letras, 1989.

SANTOS FILHO, S. Avaliação e humanização em saúde: aproximações metodológicas. Ijuí: EdUnijuí, 2009.

\section{Nota}

${ }^{1}$ Optamos por preservar a identidade do município em que foi realizado o curso de formação para trabalhadores e gestores da atenção básica. 
Formation processes within the National Humanization Politics: the experience of a course for managers and workers in primary health care

This paper aims to report the experience of a training course of the National Humanization Politics facing managers and workers of primary care in a municipality in the State of Rio de Janeiro. The course aimed at training of institutional supporters that will encourage networking in the Unified Health System (SUS), advocating for change and consolidation in the modes of attention and service management. In the methodology, we sought a way of "training area" that was based on practical concrete action by employees for health work. The course involved forty participants, managers and employees of medium and higher levels are linked to primary care, resulting from the strategy of the Family Health Units and Health The results highlight comanagement actions in the form of meetings with users to share decisions on the service, implementing a host of measures to ensure the User access the service, and extended clinic, with team discussions of clinical cases, and actions in the field of occupational health, the effect of the discussions work processes in multidisciplinary teams.

Key words: National Humanization Politics; formation process; course; primary care. 